\title{
Nasal Spray, Solution/Oromucosal Solution Dosage Form
}

National Cancer Institute

\section{Source}

National Cancer Institute. Nasal Spray, Solution/Oromucosal Solution Dosage Form. NCI

Thesaurus. Code C149688.

Liquid preparation consisting of a solution intended for use as a nasal spray or an

oromucosal solution. 